\title{
The effect of diphenylhydantoin on metabolic and growth hormone changes during and after exercise
}

\author{
RJ CHALMERS, RH JOHNSON \\ From the Department of Applied and Life Sciences The Queen's College, Glasgow, and the Wellington \\ Clinical School of Medicine, University of Otago, New Zealand.
}

SUMMARY Metabolic and human growth hormone responses to exercise were investigated in six normal healthy subjects on two occasions with and without an oral dose of diphenylhydantoin (500 mg). Serum diphenylhydantoin concentrations were similar in all subjects and were just below the accepted therapeutic range for epileptic patients. There was no significant difference in blood lactate, pyruvate or glucose concentrations with diphenylhydantoin. Plasma free fatty acids, and blood glycerol and total ketone concentrations were greater after exercise following diphenylhydantoin. Significantly greater concentrations of human growth hormone occurred during exercise with diphenylhydantoin. Further investigation of the mechanisms by which diphenylhydantoin alters lipolysis and human growth hormone release would be of value as these metabolic and hormonal effects could influence exercise tolerance in athletics and other pursuits.

Diphenylhydantoin is known to impair insulin release in response to glucose loading ${ }^{2}$ and there is evidence that it inhibits insulin release from isolated pancreas $^{3}$. Such hormonal effects may have important implications for treatment with diphenylhydantoin and it was therefore decided to investigate the effect of the drug on carbohydrate and fat metabolism in response to exercise. In addition, the effect of diphenylhydantoin on the release of growth hormone was also examined.

\section{Methods}

\section{Subjects and procedure}

Six normal healthy subjects aged $22-40$ years (mean 29) were investigated on two separate occasions. The subjects were asked to fast overnight before each investigation. On the first occasion the subjects received diphenylhydantoin (500 $\mathrm{mg}$ ) by mouth overnight and the following morning exercised on a bicycle ergometer at 100 watts for 30 minutes. On the second occasion the same subjects per-

Address for reprint requests: Dr RJ Chalmers, The Queen's College, 1 Park Drive, Glasgow G3 6LP, UK.

Received 16 March 1982, and in revised form 27 October 1982 Accepted 18 December 1982 formed an identical exercise test at least seven days later but received no medication.

Blood samples were taken from a cannula in an antecubital vein before, at 10 minute intervals during exercise and at $5,15,30,60,90$ and 120 minutes after exercise. Blood samples were analysed for lactate and pyruvate, ${ }^{4}$ acetoacetate and 3-hydroxybutyrate, ${ }^{5}$ glucose $^{6}$ and glycerol. ${ }^{7}$ Plasma samples were analysed for free fatty acids, ${ }^{8}$ growth hormone, and resting serum samples for diphenylhydantoin. ${ }^{10}$ The significance of differences were examined using the Mann-Whitney non-parametric $U$ test for small samples. ${ }^{11}$

\section{Results}

SERUM DIPHENYLHYDANTOIN

Serum concentrations of diphenylhydantoin were similar (mean 30.7 $\mu \mathrm{mol} / \mathrm{l}$ : range 23.2-44.4 $\mu \mathrm{mol} / \mathrm{l}$ ) and were just below the accepted therapeutic range $(40-80 \mu \mathrm{mol} / \mathrm{l})$ for epileptic patients. ${ }^{12}$

BLOOD LACTATE AND PYRUVATE

Basal blood lactate and pyruvate concentrations were similar on both occasions. During exercise, blood lactate reached maximum levels after 10 minutes of $3.4 \mu \mathrm{mol} / \mathrm{ml}$ and $3.1 \mu \mathrm{mol} / \mathrm{ml}$ (mean concentrations with and without diphenylhydantoin 
respectively). Blood lactate concentrations returned to normal resting levels 60 minutes after the end of exercise. The changes in pyruvate concentrations are similar. There was no significant difference between concentrations of lactate or pyruvate at any time during the investigation on the two occasions.

PLASMA FREE FATTY ACIDS (fig 1)

Basal plasma free fatty acids concentrations were not significantly different on the two occasions. There was a rise in free fatty acids concentrations towards the end of exercise on the two occasions and the mean concentrations after diphenylhydantoin were higher than the corresponding control values after exercise and were significantly greater 15 minutes after exercise $(p<0.05)$.

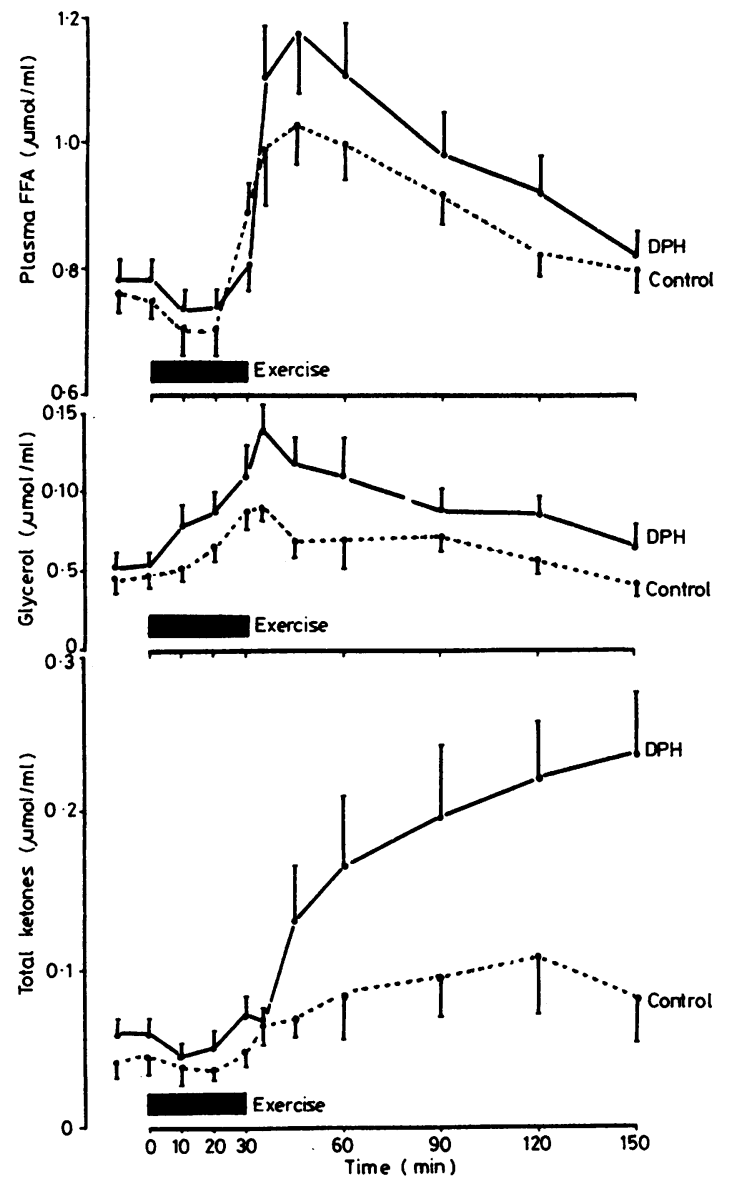

Fig 1 Plasma FFA, blood glycerol and total b̆lood ketone (acetoacetate + 3-hydroxybutyrate) concentrations ( $\mu \mathrm{mol} / \mathrm{ml}$, mean $\pm S E M)$ during and after exercise in six normal subjects with (-O) and without (-- - - ) administration of DPH (500 mg).
BLOOD GL YCEROL (fig 1)

Basal blood glycerol concentrations were similar on both occasions. Exercise was associated with a rise in blood glycerol concentrations and the glycerol concentrations after diphenylhydantoin were significantly greater than the corresponding control values at 5, 15, 30 and 60 minutes after exercise ( $p<0.01,0.01,0.05$ and 0.05 respectively).

\section{TOTAL BLOOD KETONES (fig 1)}

Basal concentrations of total ketones (acetoacetate + 3-hydroxybutyrate) were similar on both occasions. After exercise ketone concentrations rose on both occasions and the concentrations after diphenylhydantoin were significantly greater than the corresponding control values at $15,30,60,90$ and 120 minutes after exercise $(p<0.05,0.01$, 0.001 , and 0.001 respectively).

\section{BLOOD GLUCOSE}

Exercise was associated with a similar small fall in glucose concentrations on both occasions but after exercise levels returned quickly towards basal concentrations. There was no significant difference in blood glucose concentrations on the two occasions at any time during the investigation.

PLASMA GROWTH HORMONE (fig 2)

There was no significant difference in basal growth hormone concentrations on the two occasions. Exercise produced a marked rise in human growth hormone concentrations reaching a peak at the end of exercise on both occasions. Growth hormone

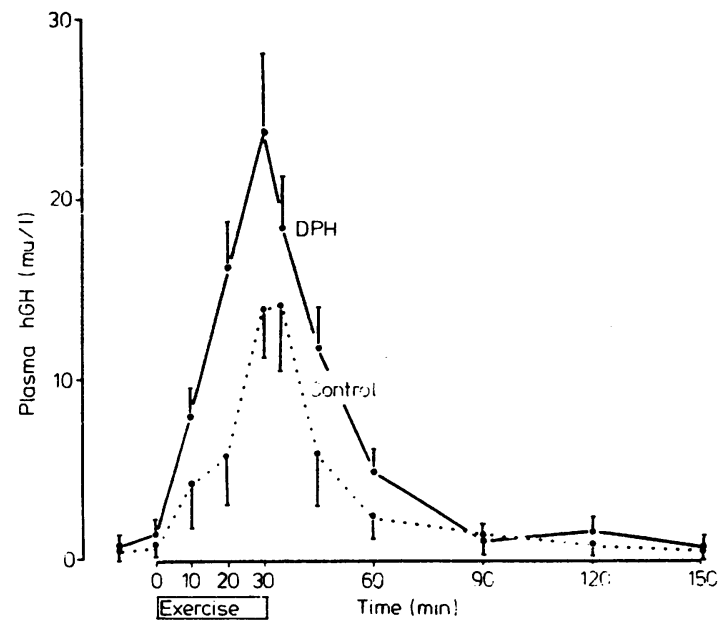

Fig 2 Plasma human growth hormone concentrations (mull, mean $\pm S E M)$ during and after exercise in six normal subjects with (๑) and without (०---๑) administration of DPH $(500 \mathrm{mg})$. 
concentration during exercise with diphenylhydantoin were significantly greater than the corresponding control concentrations at 10,20 and 30 minutes ( $\mathrm{p}<0.05,0.001$ and 0.01 respectively).

\section{Discussion}

The present observations demonstrate that a single dose of diphenylhydantoin administered to normal subjects alters metabolic and human growth hormone responses to exercise. The subjects had serum diphenylhydantoin levels just below the accepted therapeutic range but it should be noted that diphenylhydantoin was administered on the evening preceding the investigation and that the metabolic and hormonal effects relate to falling diphenylhydantoin concentrations. Administration of diphenylhydantoin for fourteen days in normal subjects has been reported to reduce the insulin response to oral glucose ${ }^{2}$ whereas other investigators did not find evidence of altered carbohydrate tolerance or insulin levels in patients receiving long term treatment with non-toxic levels of diphenylhydantoin. ${ }^{13}$ The effects of acute and chronic administration of diphenylhydantoin may vary and further studies will be required to establish if there is any evidence of similar changes in metabolic and hormonal responses in patients receiving long term treatment.

The metabolic effects associated with diphenylhydantoin in the present investigation consisted of a greater rise in free fatty acids and blood glycerol after exercise and this suggests that diphenylhydantoin produces greater lipolysis after exercise. The development of marked post exercise ketosis was also noted following diphenylhydantoin treatment. The factors responsible for the increased lipolysis associated with diphenylhydantoin treatment are unknown.

Moderate exercise has been shown to cause a rise in plasma cortisol as exercise continues, ${ }^{14}$ and diphenylhydantoin stimulates hydroxycorticoid excretion. ${ }^{15-17}$ Cortisol inhibits free fatty acids resterification and potentiates fatty acid release by adrenaline.$^{18}$ Plasma catecholamine concentrations are reported to increase with exercise ${ }^{19}$ and catecholamines promote lipolysis. ${ }^{20}$ It is not known if changes in circulating levels of cortisol or catecholamines after exercise were important factors leading to increased lipolysis after diphenylhydantoin treatment in the present study and this requires further investigation.

Ketone concentrations did not alter greatly during exercise on both occasions suggesting that ketone production and utilisation were closely matched during exercise. Treatment with diphenylhydantoin was associated with a marked rise in ketones after exercise. The greater rise in ketone concentrations is probably related to the greater lipolysis after exercise combined with a decreased aerobic oxidation through the citric acid cycle. This effect may have been produced by a reduced rate of resterification of free fatty acids after exercise. Insulin levels are known to fall during exercise and to rise immediately after exercise, paralleling changes in adrenergic activity. ${ }^{21} \mathrm{~A}$ failure of release of insulin after exercise in the subjects treated with diphenylhydantoin would be consistent with the known effects of diphenylhydantoin in inhibiting insulin release $\mathrm{e}^{1-3}$ and such an effect could delay resterification of free fatty acids as insulin is known to limit fat mobilisation. ${ }^{22}$

The present observations indicate that diphenylhydantoin produces a greater human growth hormone response to exercise. Growth hormone is known to have lipolytic properties ${ }^{23}{ }^{24}$ but the absence of an increase in human growth hormone during exercise in patients with hypopituitarism did not prevent fat mobilisation during exercise. ${ }^{25}$ It therefore seems unlikely that the greater elevation of human growth hormone produced the greater level of lipolysis after exercise in the present investigation. Hypoglycaemia ${ }^{26}$ and a fall in free fatty acids ${ }^{27}$ have been reported to stimulate human growth hormone release. These metabolic changes are unlikely to have been important stimuli in the present study as blood glucose concentrations were similar on both occasions during and after exercise and free fatty acids concentrations increased in a similar manner during exercise on both occasions. Further studies of the mechanisms by which diphenylhydantoin alters lipolysis and human growth hormone release are indicated as the increased susceptibility to ketosis after the ingestion of diphenylhydantoin could influence exercise tolerance in athletics and other pursuits.

\section{References}

' Malherbe C, Burrill KC, Levin SR, Karam JH, Forsham RH. Effect of diphenylhydantoin on insulin secretion in Man. New Engl J'Med 1972;286:339-342.

${ }^{2}$ Cudworth AF, Cunningham JL. The effect of diphenylhydantoin on insulin response. Clin Sci Mol Med 1974;46:131-136.

${ }^{3}$ Levin SR, Booker V, Smith DF, Grodsky GM. Inhibition of insulin secretion by diphenylhydantoin in isolated perfused pancreas. J Clin Endocrinol Metabol 1970;30:400-401.

${ }^{4}$ Hohorst HJ, Kreutz FH, Bucher T. Uber metabolitigehalte und metabolit-konzentrationen in der leber der ratte. Biochemische Zeitschrift 1959;332:18-46. 
5 Williamson DH, Mellanby J, Krebs HA. Enzymic determination of $\mathrm{D}(-)$ hydroxybutyrate and acetoacetic acid in blood. Biochem $J$ 1962;82:90-96.

- Bergmeyer HU, Bernt E. In: Methods of Enzymatic Analysis Bermeyer HE ed. Weinfreim. Verlag Chemie 1963:125.

${ }^{7}$ Kreutz, FH. Enzymic glycerin determination. Klin Wochenschr 1962;40:362-363.

${ }^{8}$ Itaya $\mathrm{K}, \mathrm{Ui} \mathrm{H}$. Colorimetric determination of free fatty acids in biological fluids. $J$ Lipid Research 1965;6:16-20.

9 Morgan CR. Human growth hormone immunoassay: two antibody method using ${ }^{125}$ I tracer. Pro Soc Exp Bio Med 1966;121:62-81.

${ }^{10}$ Goudie JH, Burnett D. A gas chromatographic method for simultaneous determination of phenobarbitone primidone and phenytoin in serum using a nitrogen detector. Clin Chem Acta 1973;43:423-429.

"Mann HB, Whitney DR. On a test of whether one of two random variables is stochastically larger than the other. Ann Mathematical Statistics, 1947;18:52-54.

${ }_{12}$ Drug levels in epilepsy (editorial) Lancet 1975;2:264-7.

${ }^{13}$ Callaghan N, Freely M, O'Callaghan et al. The effect of toxic and non-toxic serum phenytoin levels on carbohydrate tolerance and insulin levels. Acta Neurol Scand 1977;56:563-71.

${ }^{14}$ Sutton J, Young J, Lazarus L, Hickie J, Maksuytis J. Hormonal changes during exercise. Lancet, 1968; 2:1304-??.

${ }^{15}$ Costa PJ, Glaser GH, Bonnycastle DD. Effects of diphenylhydantoin (dilantin) on adrenal corticol function: a study in non-epileptic human subjects. Arch Neurol 1955;74:83-91.

${ }^{16}$ Krieger DT. Effect of diphenylhydantoin on pituitaryadrenal interrelation. $J$ Clin Endocrinol Metabol 1961;22:490-3.

${ }^{17}$ Dill RE. Discrepancy of adrenal responses in diphenylhydantoin treated rats. Arch Int Pharmacodyn Ther 1966;160:363-73.

${ }^{18}$ Shafir E. Kerpel S. Fatty acid resterification and release as related to the carbohydrate metabolism of adipose tissue; effect of epinephrine, cortisol and adrenalectomy. Arch Biochem Biophys 1969;105:237-44.

${ }^{19}$ Bloom SR, Johnson RH, Park DH, Rennie MJ, Sulaiman WR. Differences in the metabolic and hormonal response to exercise between racing cyclists and untrained individuals. J Physiol (Lond) 1976;258:118.

${ }^{20}$ Havel RJ, Goldfien A. The role of the sympathetic nervous system in the metabolism of free fatty acids. $J$ Lipid Research 1959;1:102-108.

${ }^{21}$ Johnson RH, Park DM, Rennie MJ, Sullaiman WR Hormonal responses to exercise in racing cyclists. $J$ Physiol (Lond) 1974;241:23P.

${ }^{21}$ Bieberdorf FA, Chernick SS, Scow RO. Effect of insulin and acute diabetes on plasma FFA and ketone-bodies in the fasting rat. $J$ Clin Invest 1970;49:1685-93.

${ }^{23}$ Hunter WM, Foneska CC, Passmore R. Growth hormone, important role in muscular exercise in adults. Science 1965;150:1051-2.

${ }^{24}$ Rabinowitz D, Klasser G, Zierber K. Effect of human growth hormone in muscle and adipose tissue metabolism in the forearm of man. $J$ Clin Invest 1965;44:51-61.

25 Johnson RH, Rennie MJ, Walter JL, Webster MHC. The effect of moderate exercise on blood metabolites in patients with hypopituitarism. Clin Sci 1971; 40:127-36.

${ }^{26}$ Roth J, Glick SH, Yalow RS, Berson SA. Hypoglycaemia a potent stimulus to secretion of growth hormone. Science 1963;140:987-8.

${ }^{27}$ Irie M, Sakuma M, Taushima T, Shizume K, Nakara K. Effect of nicotinic acid administration on plasma growth hormone concentrations. Pro Soc Exp Biol Med 1967;126:708-11. 